\title{
Risk factors for ischemic stroke in Bulgaria
}

\author{
Mihael Emilov Tsalta-Mladenov ${ }^{1,2}$, Silva Peteva Andonovaa ${ }^{1,2}$ \\ ${ }^{1}$ Department of Neurology and Neuroscience, Faculty of Medicine, \\ "Prof. Paraskev Stoyanov" Medical University, Varna, Bulgaria \\ ${ }^{2}$ Second Clinic of Neurology with ICU and Stroke unit, \\ "St. Marina" University Hospital, Varna, Bulgaria
}

\begin{abstract}
Background. Stroke is a multifactorial disease with various clinical presentations ruled out by modifiable and non-modifiable risk factors (RF). Multiple vascular and behavioural factors lead to an increased risk of ischemic stroke, as they can differ in various countries. Understanding those factors may result in the implementation of strategies for screening, prevention, and reducing the overall risk of stroke. There is a lack of contemporary information regarding the RF for ischemic stroke (IS) in Bulgaria.

Objective. We aimed to determine the major potential RF for ischemic stroke in the Bulgarian population.

Material and methods. A prospective hospital-based case-control study was conducted between July 1, 2019, and June 30, 2020, at a tertiary care referral center for neurological disorders. We included cases with first-ever and recurrent stroke and stroke-free controls. Association between RF and IS was expressed in odds ratio (OR) through a 95\% confidence interval $(\mathrm{Cl})$. Statistical significance was defined as a p-value of 0.05 or less.

Results. Overall 150 cases and 100 stroke-free participants were included. All risk factors were more prevalent in the case-group, except for dyslipidemia which had an inverse association with IS risk. The most significant RF for IS consisted of hypertension (OR, 28.78; 95\% Cl, $6.67-124.15)$ heart failure (OR, 15.25; 95\% Cl, 6.29-36.97), atrial fibrillation (OR, 11.29; 95\% Cl, 3.92-32.51), ischemic heart disease (OR, 5.83; 95\% Cl, 2.81-12.12), diabetes mellitus (OR, 2.65; 95\% Cl, 1.28-5.49), daily alcohol abuse with concentrate (OR, 9.39; $95 \% \mathrm{Cl}, 1.21-73.00)$ and current smoking (OR, 1.82; $95 \% \mathrm{Cl}, 1.00-3.32$ ).

Conclusions. The results of this study confirm the significant contribution of modifiable RF, both behavioral and related to medical conditions. Early detection and management of the major stroke RF may result in lower stroke incidence. Therefore, implementations of strategies for screening and prevention are needed to reduce the overall risk of stroke.
\end{abstract}

Keywords: ischemic stroke, stroke, risk factors, case-control study, relative risk, odds ratio, Bulgaria

\section{INTRODUCTION}

Stroke is a socially significant disease, ranked as the second most common cause of death and chronic disability in patients who survived the acute stage. Therefore, stroke is a disease of high public health importance with serious socio-economic consequences. The burden of stroke is expected to rise over the next decades because of demographic characteristics especially in developing countries (1).

Bulgaria is in one of the forefront places of stroke mortality in Europe, as the average mortality rates are three times higher than in other European countries (2). According to The Global Burden of Diseases Study from 2016, about 38,000 people get a stroke in Bulgaria every year, and about 206,000 people live in the country with the consequences of a stroke (3).

Stroke is a multifactorial disease with various clinical presentations ruled out by modifiable and non-modifiable risk factors (4).

In 2010 the international study INTERSTROKE denoted 10 modifiable risk factors that account for up to $90 \%$ of all strokes (5). The most influential of them are hypertension, diabetes mellitus, atrial fi- 
brillation, dyslipidemia, smoking, abnormal alcohol intake (6). The presence of one or a combination of these risk factors is associated with an increased risk and incidence of ischemic stroke. The strict control of these risk factors is associated with a reduced risk of cerebral infarction, as well as milder symptoms in the case of such (7). Non-modifiable factors include age, sex and race. Additionally, genetic factors can be found in $40 \%$ of idiopathic thromboembolic events. The most common causes for inherited thrombophilia are antithrombin III, protein $\mathrm{C}$, protein $\mathrm{S}$ deficiency or a mutation in factor V Leiden (F V), factor II prothrombin (F II), plasminogen activator inhibitor (PAI) and methylenetetrahydrofolate reductase (MTHFR) genes (8). Other less-well documented risk factors include geographic location, socioeconomic status, air pollution and passive smoking. They are part of local and national campaigns related to promotion of higher physical activity, non-smoking in public places, reducing the amount of sugars in food and drinks and others (9).

We can prevent up to $80 \%$ of all stroke events by early detection of risk factors, treatment of diseases linked with increased cerebrovascular risk and lifestyle modifications (10).

The present study aims to identify, in a hospital-based case-control study, the prevalence and the relative importance of various major modifiable risk factors contributing to ischemic stroke in the Bulgarian population.

\section{MATERIAL AND METHODS}

\section{Study design and participants}

Participants in the present study are part of a wider prospective study of quality of life after ischemic stroke in which participants were recruited from July 1, 2019, to June 30, 2020. The study was done at Second Clinic of Neurology with ICU and stroke unit at "Sveta Marina" University Multiprofile Hospital for Active Treatment, which is the largest center for stroke treatment in Eastern Bulgaria. All of the participants signed informed consent before the analysis and the study was approved by the ethics committee of Medical University Varna.

\section{Inclusion and exclusion criteria}

In this study were included patients with acute ischemic stroke - cases, and non-stroke patients - controls. Our study is based on consecutive cases of ischemic stroke patients hospitalized in our department. We used the American Heart Association/American Stroke Association (AHA/ASA) definition of stroke (11). Patients with first-ever and recurrent stroke were included in the study.

Additional inclusion criteria for the cases - patients with ischemic stroke were the age of 18 years or more, acute onset of neurological symptoms lasting more than 24 hours, conducted neuroimaging examination of the head - computed tomography (CT) or magnetic resonance imaging (MRI) and signed informed consent. Exclusion criteria for cases were age under 18 years, lack of neurological symptoms or the presence of such was less than 24 hours, and refusal to sign an informed consent. Patients with a transient ischemic attack (TIA) were not included in the present study.

Controls were non-stroke patients and they were included if they were 18 years of age or older, who had no anamnestic or clinical data for a previous stroke, who had at least one modifiable risk factor for ischemic stroke and signed informed consent. Controls we excluded from the study when they were younger than 18 years of age, when they had neuroimaging data for acute stroke (ischemic or hemorrhagic), when anamnestic or clinical data for a previous stroke was available and when there was a refusal to sign an informed consent.

\section{Measurement of risk factors}

All participants were interviewed by a neurologist in an as similar as possible manner to get information for comorbidities and behavioral risk factors for stroke. Demographic data, social history, and past medical records were also checked and collected. To obtain detailed information for the cases, relatives and care-givers were also interviewed. All participants underwent a medical assessment and examination including blood tests.

To accept the presence or absence of a certain risk factor, we used the following criteria:

- Hypertension - Patients enrolled in the study were diagnosed with hypertension if they were using regularly antihypertensive medications prior the enrolling in this survey, or if persistent values of systolic blood pressure $>140 \mathrm{and} /$ or diastolic $>90 \mathrm{mmHg}$ were reported during the hospital stay. 
- Diabetes mellitus was considered when the participant was taking oral hypoglycemic drugs or insulin prior the enrolling in this survey or when the blood glucose levels were higher than $11.1 \mathrm{mmol} / \mathrm{l}$ in a random blood sample followed by a blood glucose profile.

- Atrial fibrillation was considered as a risk factor when an arrhythmia was present before the enrollment in the study or it was detected during the hospital stay by standard ECG, ECG monitoring, or Holter-ECG.

- Dyslipidemia has been reported in patients who were receiving statin or fibrate therapy before the enrollment in the study or when one or more of the following founding were detected in the lipid profile of the patient:

- Total cholesterol values above 5.2 $\mathrm{mmol} / \mathrm{l}$;

- LDL cholesterol above $2.6 \mathrm{mmol} / \mathrm{l}$;

- Triglycerides above $1.7 \mathrm{mmol} / \mathrm{l}$;

- HDL cholesterol less than $1.04 \mathrm{mmol} / \mathrm{l}$;

- Smoking status - Smokers were categorized as non-smoker, current, and former smokers. Patients who had smoked tobacco in the past 3 months, including those who had quit in that period were classified as current smokers. These patients who had smoked in the past, but not in the last 3 months formed the group of former smokers. Smokers were further divided into groups according to the number of cigarettes smoked per day:

- I group (light) - 1 to 5 cigarettes a day;

- II group (moderate) - 6 to 14 cigarettes a day;

- III group (heavy) - over 15 cigarettes a day;

- Alcohol consumption - Drinkers were categorized as never and currently drinking. Patients who we consuming alcohol were further divided into groups according to the UK alcohol guidelines (12):

- Group I (Low alcohol consumption) light alcohol (e.g. beer, wine) up to 3 glasses per week; concentrate (e.g. whiskey) daily intake up to $25 \mathrm{ml}$ or $175 \mathrm{ml}$ per week;

- Group II (Moderate alcohol consumption) - light alcohol between 4-6 glasses a week with at least 1 day weekly free of alcohol; concentrate daily intake between 25 and $50 \mathrm{ml}$ or $350 \mathrm{ml}$ per week;

- Group III (Alcohol abuse) - light alcohol over 7 glasses a week without free of alcohol day; concentrate daily intake over $50 \mathrm{ml}$ or $350 \mathrm{ml}$ per week;

Additional comorbidities associated with higher cerebrovascular risk were also included in this research based on the medical documentation and the conducted consultations with relevant specialists.

\section{Statistical analysis}

We analyzed data for an unmatched case-control study. The data were quantitative and obtained at a nominal, ordinal, interval, and ratio level. The statistical analysis was performed using the software programs SPSS, version 23.00 (IBM Statistics, USA) and GraphPad Prism, version 5.00 (GraphPad Software, San Diego California, USA). Regression analysis was performed to study the functional dependence between two or more variables (dependent and independent). The odds ratio was used to quantify the strength of the association between different factors and events. Confidence intervals (CIs) were calculated for odds ratios (OR; categorical data) and differences between means (continuous, normally distributed data). Statistical significance was defined as a p-value of 0.05 or less.

\section{RESULTS}

\section{Baseline characteristics}

This study included 150 cases of ischemic stroke and 100 unmatched stroke-free controls. In the group with an ischemic stroke, there were 116 (77.3\%) with first-ever stroke and 34 (22.7\%) patients who had a previous stroke. The mean age of stroke patients was $68.8 \pm 11.4$, as for the control group- $57.2 \pm 13.0$. The gender distribution showed no significant difference in the control group, but in the stroke group the male: female ratio was 0.6. Detailed socio-demographic characteristics for the participants are shown in Table 1.

\section{Main results}

The distribution of the main cerebrovascular risk factors in the two groups shows noteworthy 
TABLE 1. Sociodemographic characteristics of case and control patients

\begin{tabular}{|c|c|c|c|c|}
\hline \multicolumn{5}{|c|}{ Sociodemographic characteristics } \\
\hline & \multicolumn{2}{|c|}{ Cases $(n=150)$} & \multicolumn{2}{|c|}{ Controls $(n=100)$} \\
\hline & $\mathbf{N}$ & $\%$ & $\mathbf{N}$ & $\%$ \\
\hline \multicolumn{5}{|l|}{ Age } \\
\hline - Mean (years) & \multicolumn{2}{|c|}{$68.8 \pm 11.4$} & \multicolumn{2}{|c|}{$57.2 \pm 13.0$} \\
\hline \multicolumn{5}{|l|}{ Sex } \\
\hline - Male & 90 & 60.0 & 48 & 48.0 \\
\hline - Female & 60 & 40.0 & 52 & 52.0 \\
\hline \multicolumn{5}{|l|}{ Residence } \\
\hline - Town & 121 & 80.7 & 81 & 81.0 \\
\hline - Village & 29 & 19.3 & 19 & 19.0 \\
\hline \multicolumn{5}{|l|}{ Education level } \\
\hline - Primary & 45 & 30.0 & 12 & 12.0 \\
\hline - Secondary & 63 & 42.0 & 50 & 50.0 \\
\hline - Tertiary & 42 & 28.0 & 38 & 38.0 \\
\hline \multicolumn{5}{|l|}{ Profession } \\
\hline - Currently working & 40 & 26.7 & 61 & 61.0 \\
\hline - Not working & 110 & 73.3 & 39 & 39.0 \\
\hline \multicolumn{5}{|l|}{ Marital status } \\
\hline - Living with someone & 133 & 88.7 & 94 & 94.0 \\
\hline - Living alone & 17 & 11.3 & 6 & 6.0 \\
\hline \multicolumn{5}{|l|}{ Ischemic stroke } \\
\hline - First-ever stroke & 116 & 77.3 & $\mathrm{~N} / \mathrm{A}$ & $\mathrm{N} / \mathrm{A}$ \\
\hline - Recurrent stroke & 34 & 22.7 & $\mathrm{~N} / \mathrm{A}$ & $\mathrm{N} / \mathrm{A}$ \\
\hline
\end{tabular}

differences. In the stroke-group, there are higher frequencies of the traditional vascular risk factors except for dyslipidemia.

The most constant risk factor for ischemic stroke was hypertension, observed in 148 (98.7\%) of the cases and $72(72.0 \%)$ of the stroke-free patients. This risk factor was significantly more widespread in the case-group ( $\mathrm{p}<0.001)$.

In the second place is dyslipidemia reported as in $112(74.7 \%)$ stroke patients and $84(84.0 \%)$ of the controls, with no significant difference between groups $(p=0.081)$. The higher frequency of this risk factor in the control group is evident, which is probably a consequence of various interacting populational, socio-economic, and genetic factors.

In the third place is the atrial fibrillation observed in $48(32.0 \%)$ of the cases and only $4(4.0 \%)$ of the stroke-free patients with a significant intergroup difference $(\mathrm{p}<0.001)$. A subsequent risk factor is diabetes mellitus found in 37 (24.7\%) stroke patients and only $11(11.0 \%)$ of the controls $(\mathrm{p}=0.008)$.

There is also a statistically significant higher incidence of other cardiovascular diseases in patients with stroke. The foremost of them is heart failure, present in $74(49.3 \%)$ of the cases, and $6(6.0 \%)$ of the stroke-free participants $(\mathrm{p}<0.001)$. Further- more ischemic heart disease $(\mathrm{p}<0.001)$ and Coronary artery disease $(p=0.032)$ are also more common in the stroke population. Regarding the data for previous myocardial infarction, a higher frequency was observed in the group of patients, but without statistical significance $(p=0.054)$.

The detailed distribution of modifiable cerebrovascular risk factors in patients with stroke (cases) and stroke-free participants (controls) in the present study are summarized in Table 2 .

TABLE 2. Distribution of the main modifiable cerebrovascular risk factors of case and control patients

\begin{tabular}{|l|c|c|c|c|c|}
\hline \multicolumn{5}{|c|}{ Cerebrovascular risk factors distribution } \\
\hline & \multicolumn{2}{|c|}{$\begin{array}{c}\text { Cases } \\
\text { (n=150) }\end{array}$} & \multicolumn{2}{c|}{$\begin{array}{c}\text { Controls } \\
\text { (n=100) }\end{array}$} & \multirow{2}{*}{ P-value } \\
\cline { 2 - 5 } & $\mathbf{N}$ & $\mathbf{\%}$ & $\mathbf{~ N}$ & \% & \\
\hline Hypertension & 148 & 98.7 & 72 & 72.0 & $<\mathbf{0 . 0 0 1}$ \\
\hline Atrial fibrillation & 48 & 32.0 & 4 & 4.0 & $<\mathbf{0 . 0 0 1}$ \\
\hline Myocardial infarction & 9 & 6.0 & 1 & 1.0 & 0.054 \\
\hline $\begin{array}{l}\text { Ischemic heart } \\
\text { disease }\end{array}$ & 59 & 39.3 & 10 & 10.0 & $<\mathbf{0 . 0 0 1}$ \\
\hline Heart failure & 74 & 49.3 & 6 & 6.0 & $<\mathbf{0 . 0 0 1}$ \\
\hline $\begin{array}{l}\text { Coronary artery } \\
\text { disease }\end{array}$ & 14 & 9.3 & 2 & 2.0 & 0.032 \\
\hline $\begin{array}{l}\text { Right-to-left cardiac } \\
\text { shunt }\end{array}$ & 1 & 0.7 & 1 & 1.0 & 1.000 \\
\hline $\begin{array}{l}\text { Cardiac valve } \\
\text { disorder }\end{array}$ & 4 & 2.7 & 1 & 1.0 & 0.651 \\
\hline Diabetes mellitus & 37 & 24.7 & 11 & 11.0 & $\mathbf{0 . 0 0 8}$ \\
\hline Dyslipidemia & 112 & 74.7 & 84 & 84.0 & 0.081 \\
\hline Systemic embolism & 10 & 6.7 & 2 & 2.0 & 0.131 \\
\hline Cancer & 10 & 6.7 & 11 & 11.0 & 0.250 \\
\hline
\end{tabular}

From the lifestyle risk factors, smoking was more common among the stroke patients than in the controls, as there was no difference in the smoking status - former $(\mathrm{p}=0.005)$ or current smoker $(p=0.048)$. In the case-group $47(31.3 \%)$ were currently smoking and $48(32.0 \%)$ were former smokers. Whereas in the control group the smoking status was respectively $20(20.0 \%)$ currently smoking and $16(16.0 \%)$ were former smokers. Non-smokers were only $55(36.7 \%)$ of the participants with ischemic stroke and $64(64.0 \%)$ of the controls and $(\mathrm{p}<0.001)$. In the case-group dominating part of the participants were heavy smokers. This trend is evident both for the current and former smokers $(\mathrm{p}<0.001)$.

Additional information concerning passive smoking (at work or home) was also obtained in this study. Higher levels of passive smoking were rendered in account in both groups, with a predominance in the case-group with a statistically significant difference $(\mathrm{p}<0.001)$. 
The second most important lifestyle risk factor is alcohol consumption. The results for this risk factor are not as definite as for smoking, but there are some differences. There is no significant difference in the rate of participants who drink alcohol, but still, there is prevalence in the case-group - $102(68.0 \%)$ as for the control-group it is $59(59.0 \%)(\mathrm{p}=0.146)$. More interesting are the findings regarding the severity of alcohol intake. The most significant differences are found in groups with alcohol abuse. As for the weekly abuse with light alcohol, there were 31 (20.7\%) patients with ischemic stroke and $9(19.0 \%)$ of the control-group $(\mathrm{p}=0.014)$. The same trend is observed for the daily abuse with concentrate -13 $(8.7 \%)$ of the stroke patients and only $1(1.0 \%)$ of the stroke-free participants $(p=0.010)$.

Detailed information regarding the lifestyle modifiable risk factors in patients with stroke (cases) and stroke-free participants (controls) in the present study are summarized in Table 3.

TABLE 3. Distribution of modifiable lifestyle risk factors of case and control patients

\begin{tabular}{|c|c|c|c|c|c|}
\hline \multicolumn{6}{|c|}{ Lifestyle risk factors distribution } \\
\hline & \multicolumn{2}{|c|}{$\begin{array}{c}\text { Cases } \\
(n=150)\end{array}$} & \multicolumn{2}{|c|}{$\begin{array}{l}\text { Controls } \\
(n=100)\end{array}$} & \multirow[t]{2}{*}{ P-value } \\
\hline & $\mathbf{N}$ & $\%$ & $\mathbf{N}$ & $\%$ & \\
\hline $\begin{array}{l}\text { Smoker (current and } \\
\text { former) }\end{array}$ & 95 & 63.3 & 36 & 36.0 & $<0.001$ \\
\hline Non-Smoker & 55 & 36.7 & 64 & 64.0 & $<0.001$ \\
\hline Current smoker & 47 & 31.3 & 20 & 20.0 & 0.048 \\
\hline - Light smoking & 1 & 0.7 & 2 & 2.0 & 0.360 \\
\hline - Moderate smoking & 19 & 12.7 & 15 & 15.0 & 0.604 \\
\hline - Heavy smoking & 26 & 17.3 & 3 & 3.0 & $<0.001$ \\
\hline Former smoker & 48 & 32.0 & 16 & 16.0 & 0.005 \\
\hline - Light smoking & 6 & 4.0 & 7 & 7.0 & 0.296 \\
\hline - Moderate smoking & 13 & 8.7 & 5 & 5.0 & 0.269 \\
\hline - Heavy smoking & 30 & 20.0 & 4 & 4.0 & $<0.001$ \\
\hline Passive smoking & 104 & 69.3 & 45 & 45.0 & $<0.001$ \\
\hline Alcohol consumption & 102 & 68.0 & 59 & 59.0 & 0.146 \\
\hline No alcohol intake & 48 & 32.0 & 41 & 41.0 & 0.146 \\
\hline \multicolumn{6}{|l|}{ Light alcohol (Weekly) } \\
\hline - Low consumption & 20 & 13.3 & 18 & 18.0 & 0.311 \\
\hline $\begin{array}{l}\text { - Moderate } \\
\text { consumption }\end{array}$ & 22 & 14.7 & 20 & 20.0 & 0.273 \\
\hline - Abuse & 31 & 20.7 & 9 & 9.0 & 0.014 \\
\hline \multicolumn{6}{|l|}{ Concentrate (Daily) } \\
\hline - Low consumption & 1 & 0.7 & 2 & 2.0 & 0.360 \\
\hline $\begin{array}{l}\text { - Moderate } \\
\text { consumption }\end{array}$ & 14 & 9.3 & 3 & 3.0 & 0.052 \\
\hline - Abuse & 13 & 8.7 & 1 & 1.0 & 0.010 \\
\hline \multicolumn{6}{|l|}{ Concentrate (Weekly) } \\
\hline - Low consumption & 28 & 18.7 & 18 & 18.0 & 0.890 \\
\hline $\begin{array}{l}\text { - Moderate } \\
\text { consumption }\end{array}$ & 15 & 10.0 & 6 & 6.0 & 0.265 \\
\hline - Abuse & 5 & 3.3 & 1 & 1.0 & 0.243 \\
\hline
\end{tabular}

To analyze the risk for ischemic stroke, we compared the data from the risk profiles in patients with ischemic stroke and those in the control group. Statistically significant differences were observed concerning hypertension, atrial fibrillation, ischemic heart disease, heart failure, diabetes mellitus, and to a lesser extent, Coronary artery disease $(\mathrm{p}<0.05)$.

From all the factors we studied, hypertension is associated with the highest risk of ischemic stroke - 28.78 (95\% CI 6.67 - 124.15) times. Presence of heart failure and atrial fibrillation are associated with 15.25 (95\% CI 6.29-36.97) and respectively 11.29 (95\% CI 3.92-32.51) times higher risk for ischemic stroke. The presence of diabetes mellitus is associated with 2.65 (95\% CI 1.28-5.49) times increased risk, while ischemic heart disease and Coronary artery disease are associated with respectively $5.83(95 \%$ CI 2.81-12.12) and 5.04 (95\% CI 1.12-22.70) times higher risk.

In this study dyslipidemia, as a risk factor for cerebrovascular disease, did not show a statistically significant increase in the overall risk for ischemic stroke $(p=0.086)$.

The study also showed a statistically significant higher risk in the presence of behavioral risk factors $(p<0.05)$. The data for smoking (both current and former) has the greatest importance -3.07 (95\% CI $1.81-5.18)$ times increased risk of ischemic stroke. There is also evidence of higher risk in the subgroup of former smokers compared to current ones. Regarding passive smoking, there is a relatively high risk for ischemic cerebrovascular events, comparable to active smoking- 2.76 (95\% CI 1.63-4.67).

The risk from weekly abuse with light alcohol is 2.63 (95\% CI 1.19-5.81) times higher, and for concentrate- 3.41 (95\% CI 0.39-29.67) times. Daily alcohol abuse with concentrate is associated with more than 9 times higher risk of cerebral infarction- 9.39 (95\% CI 1.21-73.00).

All investigated factors predicting the risk of ischemic stroke are presented in Table 4.

\section{DISCUSSION}

In this study, we demonstrated the most common modifiable risk factors for ischemic stroke in the Bulgarian population.

The most widespread traditional risk factors were hypertension $(98.7 \%)$, followed by dyslipi- 
TABLE 4. Factors predicting ischemic stroke risk

\begin{tabular}{|c|c|c|c|c|c|}
\hline \multicolumn{6}{|c|}{ Factors predicting ischemic stroke risk in the Bulgarian population } \\
\hline \multirow{2}{*}{ Risk factor } & \multicolumn{2}{|c|}{ Odds ratio (OR) } & \multirow{2}{*}{ P-Value } & \multicolumn{2}{|c|}{ Relative risk (RR) } \\
\hline & OR & $95 \% \mathrm{Cl}$ & & $\mathbf{R R}$ & $95 \% \mathrm{Cl}$ \\
\hline Hypertension & 28.78 & $6.67-124.15$ & $<0.001$ & 1.37 & $1.21-1.55$ \\
\hline Atrial fibrillation & 11.29 & $3.92-32.51$ & $<0.001$ & 1.41 & $1.26-1.59$ \\
\hline Myocardial infarction & 6.32 & $0.79-50.68$ & 0.054 & 1.05 & $1.01-1.10$ \\
\hline Ischemic heart disease & 5.83 & $2.81-12.12$ & $<0.001$ & 1.48 & $1.28-1.71$ \\
\hline Heart failure & 15.25 & $6.29-36.97$ & $<0.001$ & 1.85 & $1.57-2.19$ \\
\hline Coronary artery disease & 5.04 & $1.12-22.70$ & 0.032 & 1.08 & $1.02-1.15$ \\
\hline Right-to-left cardiac shunt & 0.66 & $0.04-10.75$ & 1.000 & 1.00 & $0.97-1.02$ \\
\hline Cardiac valve disorder & 2.71 & $0.30-24.63$ & 0.651 & 1.02 & $0.98-1.05$ \\
\hline Diabetes mellitus & 2.65 & $1.28-5.49$ & 0.008 & 1.18 & $1.05-1.32$ \\
\hline Dyslipidemia & 0.56 & $0.29-1.07$ & 0.086 & 0.63 & $0.37-1.07$ \\
\hline Systemic embolism & 3.50 & $0.75-16.33$ & 0.131 & 1.05 & $1.00-1.10$ \\
\hline Cancer & 0.58 & $0.24-1.42$ & 0.250 & 0.95 & $0.88-1.03$ \\
\hline Smoker (current and former) & 3.07 & $1.81-5.18$ & $<0.001$ & 1.76 & $1.32-2.35$ \\
\hline Current smoker & 1.82 & $1.00-3.32$ & 0.049 & 1.57 & $0.991-2.48$ \\
\hline Former smoker & 2.47 & $1.31-4.66$ & 0.005 & 2.00 & $1.205-3.32$ \\
\hline Passive smoking & 2.76 & $1.63-4.67$ & $<0.001$ & 1.54 & $1.210-1.96$ \\
\hline Alcohol abuse - light alcohol (weekly) & 2.63 & $1.19-5.81$ & 0.016 & 2.30 & $1.143-4.61$ \\
\hline Alcohol abuse - concentrate (weekly) & 3.41 & $0.39-29.67$ & 0.266 & 3.33 & $0.395-28.11$ \\
\hline Alcohol abuse - concentrate (daily) & 9.39 & $1.21-73.00$ & 0.032 & 8.67 & $1.151-65.21$ \\
\hline
\end{tabular}

demia $(74.7 \%)$, heart failure $(49.3 \%)$, ischemic heart disease $(39.3 \%)$, atrial fibrillation $(32.0 \%)$ and diabetes mellitus (24.7\%). Regarding the lifestyle risk factors it is notable that $63.3 \%$ of the stroke patients were smokers at some point in their lives $-31.3 \%$ current smokers and $32.0 \%$ former. The portion of passive smokers was also notably high $-69.3 \%$. Alcohol consumption was reported in more than two-thirds of the patients with is- chemic stroke (68.0\%). The results are consistent with previous reports for our population $(13,14)$. Besides this, there are some differences in comparison with other European countries shown in Table $5(15-23)$.

In our population, there is a much higher prevalence of hypertension, dyslipidemia, and lifestyle risk factors such as smoking and abnormal alcohol intake. Both hypertension and dyslipidemia, tend

TABLE 5. Stroke risk factors in other European countries

\begin{tabular}{|c|c|c|c|c|c|c|c|c|c|c|}
\hline \multicolumn{11}{|c|}{ Comparison of frequencies of major vascular risk factors in different European countries } \\
\hline Author & Year & Country & $\begin{array}{c}\text { Age } \\
\text { mean }\end{array}$ & $\begin{array}{c}\text { HTN } \\
(\%)\end{array}$ & $\begin{array}{l}\mathrm{AF} \\
(\%)\end{array}$ & $\begin{array}{l}\text { DM } \\
(\%)\end{array}$ & $\begin{array}{l}\mathrm{DL} \\
(\%)\end{array}$ & $\begin{array}{l}\text { CAD } \\
(\%)\end{array}$ & $\begin{array}{l}\text { CS } \\
(\%)\end{array}$ & $\begin{array}{l}\text { AA } \\
\text { (\%) }\end{array}$ \\
\hline Grau A. (15) & 2001 & Germany & 65.9 & 66.6 & 26.1 & 28.5 & 35.3 & 24.0 & 27.8 & 10.3 \\
\hline Béjot Y. (16) & 2008 & France & 74.2 & 62.1 & N/A & 17.2 & 45.5 & N/A & 23.8 & $\mathrm{~N} / \mathrm{A}$ \\
\hline Vega T. (17) & 2009 & Spain & 61.2 & 58.2 & N/A & 26.0 & 29.8 & 29.8 & 14.4 & 10.9 \\
\hline \multirow{5}{*}{ Malmivaara A. (18) } & \multirow{5}{*}{2015} & Finland & 72.6 & 70.9 & 9.1 & 20.0 & N/A & 13.3 & $\mathrm{~N} / \mathrm{A}$ & $\mathrm{N} / \mathrm{A}$ \\
\hline & & Hungary & 69.5 & 76.5 & 4.5 & 21.7 & $\mathrm{~N} / \mathrm{A}$ & 6.9 & $\mathrm{~N} / \mathrm{A}$ & $\mathrm{N} / \mathrm{A}$ \\
\hline & & Italy & 73.8 & 65.4 & 3.7 & 23.2 & $\mathrm{~N} / \mathrm{A}$ & 3.6 & $\mathrm{~N} / \mathrm{A}$ & $\mathrm{N} / \mathrm{A}$ \\
\hline & & $\begin{array}{l}\text { The } \\
\text { Netherlands }\end{array}$ & 71.6 & 77.2 & 2.7 & 19.6 & N/A & N/A & N/A & $\mathrm{N} / \mathrm{A}$ \\
\hline & & Sweden & 76.2 & 70.3 & 9.0 & 16.8 & N/A & N/A & $\mathrm{N} / \mathrm{A}$ & $\mathrm{N} / \mathrm{A}$ \\
\hline Correia M. (19) & 2016 & Portugal & 75.4 & 72.8 & 18.5 & 24.9 & 45.2 & N/A & 19.3 & $\mathrm{~N} / \mathrm{A}$ \\
\hline Tsivgoulis G. (20) & 2017 & Greece & 75.0 & 81.1 & 34.3 & 26.3 & 67.0 & 16.9 & 22.5 & 17.3 \\
\hline Köseoğlu Toksoy C. (21) & 2018 & Turkey & 63.3 & 85.5 & N/A & 33.7 & 48.2 & N/A & 26.5 & $\mathrm{~N} / \mathrm{A}$ \\
\hline Rostohar-Bijelić B. (22) & 2019 & Croatia & 71.6 & 81.6 & 19.5 & 24.1 & 66.9 & N/A & 15.5 & 11.5 \\
\hline Clery A. (23) & 2019 & England & 75.3 & 66.1 & 13.8 & 22.3 & N/A & N/A & 28.8 & 54.4 \\
\hline
\end{tabular}

HTN - hypertension; AF - atrial fibrillation; DM - diabetes mellitus; $D L$ - dyslipidemia; CAD - coronary artery disease; $C S$ - current smoker; AA - alcohol abuse 
to be with higher prevalence in the Balkan countries in comparison to other European countries.

This study also provides estimates of the relative risk for ischemic stroke concerning different modifiable risk factors. Our data represent hypertension, atrial fibrillation, ischemic heart disease, heart failure, coronary artery disease diabetes mellitus, the status of current, former and passive smoker, and abnormal alcohol intake, as significantly associated with ischemic stroke risk factors.

Hypertension is the most important modifiable risk factor associated with the highest risk for ischemic stroke among our population (OR 28.78, 95\% CI 6.67 - 124.15). Meta-analyses of randomized-control trials (RCTs) have reported a decrease of the total risk for first-ever and recurrent stroke in $30-40 \%$ only by administering adequate blood pressure (BP) lowering therapy (24). It is widely known that blood pressure reduction of 10 $\mathrm{mmHg}$ systolic and $5 \mathrm{mmHg}$ diastolic is linked with a $40 \%$ reduction in the stroke risk. Besides this, every $10 \mathrm{mmHg}$ increase in the systolic blood pressure is linked to an increased risk of $4.2 \%$ (25). Furthermore, stroke risk in hypertensives is associated with co-existence with other risk factors, which tends to follow an additive model (26). This is the reason why we should address not the single factor but the whole risk profile of the patient.

Dyslipidemia is found in $74.7 \%$ of all participants with ischemic stroke, but there was also a high prevalence in the stroke-free population. Therefore it was found that this risk factor was not a significant predictor for ischemic stroke in this study (OR, 0.56; 95\% CI, 0.29-1.07) ( $\mathrm{p}=0.086)$. In previous studies in our country was found a prevalence of dyslipidemia in up to $66.7 \%$ of the female and $69.0 \%$ of the male population (27). According to the EUROASPIRE IV study, this risk factor is found in more than $86 \%$ of the population with high vascular risk in our country (28). Nevertheless, cholesterol levels are determined by multiple genetic, environmental, and dietary factors. This might be one of the possible reasons for the higher prevalence of dyslipidemia in our population. Despite the variations in the lipid profile, this risk factor is still associated with negative health-related outcomes. Therefore early detection of dyslipidemia and normalization of the lipid levels are advisable for the general population (29).

Atrial fibrillation is associated with a 10 times higher risk for ischemic stroke in our population
(OR, 11.29; 95\% CI, 3.92-32.51). One-third of all ischemic strokes due to cardio-embolism have a history of atrial fibrillation (30). The proportion of cardio-embolic associated with atrial fibrillation increases progressively with age as it accounts for up to $36 \%$ of the cases who are aged $80-89$ years (31). Due to the aging population in our country, the percentage of patients with atrial fibrillation is increasing. In previous studies, a high risk for embolism and low levels of anticoagulation were reported in patients of 75 years of age or more (32). Another possible reason might be a higher prevalence of thrombosis of the left atrium (33). Because of all these facts, it is required early screening, detection, and initiation of therapy that aims to reduce the risk of AF-associated stroke (34).

Diabetes mellitus is responsible for 2.65 times higher risk of ischemic stroke (OR, 2.65; 95\% CI, 1.28-5.49). Hyperglycemia and diabetes mellitus are both risk factors for stroke and predictors of poor prognosis in stroke patients $(\mathrm{OR}=1.87 ; 95 \%$ CI 1.43-2.45) (35). They are also associated with an increased risk of fatal outcome (36). Therefore strict control of the glucose levels in all patients is advisable. Optimal antidiabetic treatment in combination with lifestyle changes such as weight control, diet, and increasing physical activities can be beneficial in high-risk individuals (37).

Current smokers are at 1.82 times greater risk for ischemic stroke (OR, 1.82; 95\% CI, 1.00-3.32). With even higher risk are those who are passive smokers (OR, 2.76; 95\% CI, 1.63-4.67). In current smokers, there is 2-4 times increased risk for stroke in comparison with non-smokers (38). Another study reports 6 times increased risk of ischemic stroke in the group of smokers (39). There is a growing interest in passive smoking as a risk factor in the last decades. There are reports of 1.5 times increased stroke risk in passive smokers (OR, 1.51; 95\% CI, 1.14-1.99) (40). The more cigarettes being smoked, the higher risk of stroke is estimated. For example, the use of 1-10 cigarettes/ day is associated with 2.2 times increased risk, 11$20-2.5$ times, 21-39-4.3 times, and for 40 or more cigarettes/day -9.1 times increased stroke risk (41). Cigarette smoking is a well-established risk factor for stroke and many other vascular diseases. There is the utmost need for reinforcement of the awareness of healthcare organizations and the population for the reduction of tobacco use in 
order the reduce the burden of related diseases (38).

The association between alcohol intake and risk of ischemic was addressed in numerous studies and it remains controversial (42). We found that daily alcohol abuse with concentrate (OR, 9.39; 95\% CI, 1.21-73.00) and weekly abuse with light alcohol (OR, 2.63; 95\% CI, 1.19-5.81) are associated with a statistically significant increase in the stroke risk. Previous case-control studies demonstrated the U-shaped relationship between alcohol consumption and stroke. Low and moderate alcohol intake has a protective effect, while alcohol abuse is associated with a higher risk of stroke (43). However, due to the well-described harmful effects of heavy alcohol consumption on vascular and non-vascular conditions, all patients should be encouraged to control this lifestyle risk factor. Care should be taken on a populational level when making general recommendations about safe levels of alcohol intake because it would do substantially more harm than good (44).

We acknowledge some limitations in our study. First, the study was conducted in a tertiary care referral center for neurological diseases, and may, therefore, be biased toward more disabling stroke cases with more severe comorbidities. We studied a relatively small population divided into an unequal ratio of patients with ischemic stroke (cases) and stroke-free controls. Furthermore, we did not include all lifestyle risk factors like physical activity, diet, body mass index (BMI), and there were no risk factors related to women's reproductive health such as anti-contraceptive intake. A larger prospective study might be of interest to address the association between ischemic stroke and other well-described risk factors, which did not reach statistical significance or were not analyzed in our study.

\section{CONCLUSIONS}

The results of this study are in coherence with others focusing on the risk profile for ischemic stroke. Our investigation is in confirmation of the significant contribution of hypertension, atrial fibrillation, diabetes mellitus, ischemic heart disease, heart failure, coronary artery disease, cigarette smoking, and alcohol abuse for the significant increase of the total ischemic stroke risk in the Bulgarian population. The high prevalence and importance of all the investigated risk factors also suggest the need for a multidisciplinary approach to ischemic stroke patients. It is of utmost importance to implement strategies for prevention on these pathologies and conditions to reduce the overall risk of ischemic stroke.

9. Seshadri S, Debette S. Risk Factors for Cerebrovascular Disease and Stroke. Oxford University Press, 2016, p.489.

10. Allen CL, Bayraktutan U. Risk factors for ischaemic stroke. International Journal of Stroke. 2008;3:105-16.

11. Sacco RL, Kasner SE, Broderick JP, et al. An updated definition of stroke for the 21st century: a statement for healthcare professionals from the American Heart Association/American Stroke Association. Stroke. 2013;44:2064-89.

12. Rosenberg G, Bauld L, Hooper L, Buykx P, Holmes J, Vohra J. New national alcohol guidelines in the UK: public awareness, understanding and behavioural intentions. J Public Health (Oxf). 2018:40:549-56.

13. Manchev I, Mineva P, Hadjiev D. Prevalence of Stroke Risk Factors and Their Outcomes. Cerebrovasc Dis. 2001;12:303-7.

14. Tsalta-Mladenov ME, Dimitrova VK, Georgieva D, Andonova S. Study on the risk profile of patients with acute stroke hospitalized in the Second Clinic of Neurology, St. Marina University Hospital. Varna Medical Forum. 2019, p. 73-8.

15. Grau AJ, Weimar C, Buggle F, et al. Risk factors, outcome, and treatment in subtypes of ischemic stroke: the German stroke data bank. Stroke. 2001;32:2559-66.

16. Bejot Y, Caillier M, Ben Salem D, Couvreur G, Rouaud O, Osseby GV, Durier J, Marie C, Moreau T, Giroud M. Ischaemic stroke subtypes and associated risk factors: a French population based study. J Neurol Neurosurg Psychiatry. 2008 Dec;79(12):1344-8. 
17. Vega T, Zurriaga O, Ramos JM, Gil M, Alamo R, Lozano JE, López A, Miralles MT, Vaca P, Alvarez Mdel M; Group of research for the RECENT project. Stroke in Spain: epidemiologic incidence and patterns; a health sentinel network study. J Stroke Cerebrovasc Dis. 2009 Jan;18(1):11-6.

18. Malmivaara A, Meretoja A, Peltola M, Numerato D, Heijink R, Engelfriet P, Wild SH, Belicza É, Bereczki D, Medin E, Goude F, Boncoraglio G, Tatlisumak T, Seppälä T, Häkkinen U. Comparing ischaemic stroke in six European countries. The EuroHOPE register study. Eur J Neurol. 2015 Feb;22(2):284-91, e25-6.

19. Correia M, Magalhães R, Felgueiras R, Quintas C, Guimarães L, Silva MC. Changes in stroke incidence, outcome, and associated factors in Porto between 1998 and 2011. Int J Stroke. 2017 Feb;12(2):169-179.

20. Tsivgoulis G, Patousi A, Pikilidou M, et al. Stroke Incidence and Outcomes in Northeastern Greece: The Evros Stroke Registry. Stroke. 2018;49:288-95

21. Köseoğlu Toksoy C, Bölük C, Türk Börü Ü, et al. Stroke Prevalence in a Coastal Town on the Black Sea Coast in Turkey: Community Based Study. Neurol Res Int. 2018;2018:8246123.

22. Rostohar Bijelić B, Petek M, Kadojić M, Bijelić N, Kadojić D. Distribution of Stroke Risk Factors in Eastern Croatia. Acta Clin Croat. 2018;57:103-9.

23. Clery A, Bhalla A, Bisquera A, Skolarus LE, Marshall I, McKevitt C, Rudd A, Sackley C, Martin FC, Manthorpe J, Wolfe C, Wang Y. Long-Term Trends in Stroke Survivors Discharged to Care Homes: The South London Stroke Register. Stroke. 2020 Jan;51(1):179-185.

24. Boan AD, Lackland DT, Ovbiagele B. Lowering of blood pressure for recurrent stroke prevention. Stroke. 2014;45:2506-13.

25. Leonardi-Bee J, Bath PM, Phillips SJ, Sandercock PA. Blood pressure and clinical outcomes in the International Stroke Trial. Stroke. 2002;33:1315-20.

26. Du X, McNamee R, Cruickshank K. Stroke Risk from Multiple Risk Factors Combined with Hypertension: A Primary Care Based Case-control Study in a Defined Population of Northwest England. Annals of Epidemiology. 2000;10:380-8.

27. Borissova AM, Shinkov A, Vlahov JD, Dakovska LN, Todorov TC. Dyslipidemia - Prevalence in Bulgarian population today. Endocrinologia. 2015;20:163-72.

28. Kotseva K, Wood D, De Bacquer D, et al. EUROASPIRE IV: A European Society of Cardiology survey on the lifestyle, risk factor and therapeutic management of coronary patients from 24 European countries. European Journal of Preventive Cardiology. 2016; 23:636-48.

29. Kim MK, Han K, Kim HS, et al. Cholesterol variability and the risk of mortality, myocardial infarction, and stroke: a nationwide populationbased study. Eur Heart J. 2017;38:3560-6.

Conflict of interest: none declared

Financial support: none declared
30. Freedman B, Potpara TS, Lip GY. Stroke prevention in atrial fibrillation. Lancet (London, England). 2016;388:806-17.

31. Arboix A, Cendrós V, Besa M, et al. Trends in risk factors, stroke subtypes and outcome. Cerebrovascular Diseases. 2008;26:509-16.

32. Kisheva A, Yotov Y, Angelov A, Mircheva L, Kunchev O, A. Penev A. Risk assessment and anticoagulation treatment in patients with nonvalvular atrial fibrillation in hospital setting. Clinical Medicine (Bulg). 2012;1:21-4.

33. Fadhlullah AA, Abdalgbar AA, Altalhi HK. Non rheumatic atrial fibrillation as risk of stroke. Am J Internal Med. 2016;4:117.

34. Alshehri AM. Stroke in atrial fibrillation: Review of risk stratification and preventive therapy. J Family Community Med. 2019;26:92-7.

35. Weir CJ, Murray GD, Dyker AG, Lees KR. Is hyperglycaemia an independent predictor of poor outcome after acute stroke? Results of a long-term follow up study. BMJ. 1997 May 3;314(7090):1303-6.

36. Yaneva Z, Boyadzhieva M, Hristozov K, Tsalta-Mladenov M. Stress Hyperglycemia in Patients with Acute Ischemic Stroke. Endocrinology. 2018;3:151-60.

37. Chen R, Ovbiagele B, Feng W. Diabetes and Stroke: Epidemiology, Pathophysiology, Pharmaceuticals and Outcomes. Am J Med Sci. 2016 Apr;351(4):380-6.

38. Shah RS, Cole JW. Smoking and stroke: the more you smoke the more you stroke. Expert Rev Cardiovasc Ther. 2010;8:917-32.

39. Bonita R, Duncan J, Truelsen T, Jackson RT, Beaglehole R. Passive smoking as well as active smoking increases the risk of acute stroke. Tobacco Control. 1999;8:156-60.

40. Iribarren C, Darbinian J, Klatsky AL, Friedman GD. Cohort study of exposure to environmental tobacco smoke and risk of first ischemic stroke and transient ischemic attack. Neuroepidemiology. 2004;23:38-44.

41. Bhat VM, Cole JW, Sorkin JD, et al. Dose-response relationship between cigarette smoking and risk of ischemic stroke in young women. Stroke. 2008;39:2439-43.

42. Mukamal KJ, Chung H, Jenny NS, et al. Alcohol use and risk of ischemic stroke among older adults: the cardiovascular health study. Stroke. 2005;36:1830-4.

43. Christensen AI, Nordestgaard BG, Tolstrup JS. Alcohol Intake and Risk of Ischemic and Haemorrhagic Stroke: Results from a Mendelian Randomisation Study. J Stroke. 2018;20:218-27.

44. Emberson JR, Bennett DA. Effect of alcohol on risk of coronary heart disease and stroke: causality, bias, or a bit of both? Vasc Health Risk Manag. 2006;2:239-49. 